\title{
Correction to: Changes in dairy product consumption and subsequent type 2 diabetes among individuals with prediabetes: Tehran lipid and glucose study
}

\author{
Emad Yuzbashian ${ }^{1,2}$, Golaleh Asghari ${ }^{1,3}$, Parvin Mirmiran ${ }^{1,3^{*}}$, Catherine B. Chan ${ }^{2,4}$ and Fereidoun Azizi ${ }^{5}$
}

Correction to: Nutr J 20, 88 (2021).

https://doi.org/10.1186/s12937-021-00745-x

Following publication of the original article [1], it came to the authors' attention that affiliations 1 and 2 had been erroneously swapped.

Namely, 'Department of Agricultural, Food and Nutritional Science, University of Alberta, Edmonton, Alberta, Canada' was written in place of 'Nutrition and Endocrine Research Center, Research Institute for Endocrine Sciences, Shahid Beheshti University of Medical Sciences, Tehran, Iran', and vice versa.

The error has since been corrected in the original article and the corrected affiliation information may be seen in this correction.

The authors apologize for any inconvenience caused. of Medical Sciences, Tehran, Iran. ${ }^{4}$ Department of Physiology, University of Alberta, Edmonton, Alberta, Canada. ${ }^{5}$ Endocrine Research Center, Research Institute for Endocrine Sciences, Shahid Beheshti University of Medical Sciences, Tehran, IR, Iran.

Published online: 22 December 2021

\section{Reference}

1. Yuzbashian E, et al. Changes in dairy product consumption and subsequent type 2 diabetes among individuals with prediabetes: Tehran lipid and glucose study. Nutr J. 2021;20(1):88.

\begin{abstract}
Author details
${ }^{1}$ Nutrition and Endocrine Research Center, Research Institute for Endocrine Sciences, Shahid Beheshti University of Medical Sciences, Tehran, Iran. ${ }^{2}$ Department of Agricultural, Food and Nutritional Science, University of Alberta, Edmonton, Alberta, Canada. ${ }^{3}$ Department of Clinical Nutrition and Dietetics, Faculty of Nutrition Sciences and Food Technology, National Nutrition and Food Technology Research Institute, Shahid Beheshti University
\end{abstract}

The original article can be found online at https://doi.org/10.1186/s12937021-00745-x

\footnotetext{
*Correspondence: mirmiran@endocrine.ac.ir

${ }^{3}$ Department of Clinical Nutrition and Dietetics, Faculty of Nutrition Sciences and Food Technology, National Nutrition and Food Technology Research Institute, Shahid Beheshti University of Medical Sciences, Tehran, Iran

Full list of author information is available at the end of the article
}

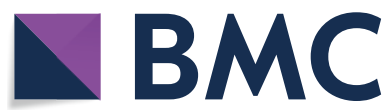

(c) The Author(s) 2021. Open Access This article is licensed under a Creative Commons Attribution 4.0 International License, which permits use, sharing, adaptation, distribution and reproduction in any medium or format, as long as you give appropriate credit to the original author(s) and the source, provide a link to the Creative Commons licence, and indicate if changes were made. The images or other third party material in this article are included in the article's Creative Commons licence, unless indicated otherwise in a credit line to the material. If material is not included in the article's Creative Commons licence and your intended use is not permitted by statutory regulation or exceeds the permitted use, you will need to obtain permission directly from the copyright holder. To view a copy of this licence, visit http://creativecommons.org/licenses/by/4.0/. The Creative Commons Public Domain Dedication waiver (http://creativeco mmons.org/publicdomain/zero/1.0/) applies to the data made available in this article, unless otherwise stated in a credit line to the data. 